\title{
The Effect of Lactococcus lactis Starter Cultures on the Oxidative Stability of Liquid Whey*
}

\author{
R. M. Tomaino, L. G. Turner, and D. K. Larick \\ Department of Food Science, \\ North Carolina State University, Raleigh 27695
}

\begin{abstract}
The oxidative stability of liquid Cheddar cheese whey was evaluated using 2 Lactococcus lactis starter cultures in combination and alone along with a control, utilizing glucono- $\delta$-lactone for acid development. Fresh and stored whey were evaluated for volatile composition, free fatty acids, and flavor by descriptive sensory analysis. A significant increase in volatile lipid oxidation products, most notably, hexanal, occurred during storage, and a corresponding decline in the free fatty acid linoleic acid was found. The flavor and aroma characteristic, cardboardy, was correlated to the increase in volatile lipid oxidation products and the decline in linoleic acid. Evidence strongly suggested that lipid oxidation was initiated during whey production and escalated during storage and that the starter cultures significantly influenced the level of volatile lipid oxidation products. Further understanding of the impact of starter cultures on whey may allow for the production of higher quality whey ingredients with wider food application.
\end{abstract}

(Key words: Lactococcus lactis, oxidative stability, whey)

Abbreviation key: GDL = glucono- $\delta$-lactone, MM170 = Lactococcus lactis spp. cremoris, MM380 = Lactococcus lactis spp. lactis, MM380/170 = a combination of Lactococcus lactis spp. lactis and Lactococcus lactis spp. cremoris, VLOP = volatile lipid oxidation products, $\mathbf{W P C}=$ whey protein concentrate, $\mathbf{W P I}=$ whey protein isolate.

\section{INTRODUCTION}

Whey protein ingredients have the potential for greater utilization in food applications. Their functional

\footnotetext{
Received April 2, 2003.

Accepted September 17, 2003.

Corresponding author: D. K. Larick; e-mail: duane_larick@ ncsu.edu.

*Paper No. FSR00-40 of the Journal Series of the Department of Food Science, North Carolina State University, Raleigh. The research reported in this publication was funded by the North Carolina Dairy Foundation and the Southeast Dairy Research Center. The use of trade names in this publication does not imply endorsement by the North Carolina Research Service nor criticism of ones not mentioned.
}

(Morr and Ha, 1993; Jayaprakasha and Brueckner, 1999) and nutritional properties (Regester et al., 1996) are well documented, yet only $51.2 \%$ of liquid whey produced in the United States is further processed into food or feed ingredients (American Dairy Products Institute, 2002). Morr and $\mathrm{Ha}$ (1991) stated that the agedstale off flavor that develops in dried whey products limits their greater utilization as food ingredients. Results from liquid extraction (Ferretti and Flanagan, 1971a, 1971b; Mills and Broome, 1998), headspace (Mills, 1986; Lee and Morr, 1994; Laye et al., 1995; Lee et al., 1996), and solid-phase microextraction (Stevenson and Chen, 1996; Yang et al., 1998; Quach et al., 1999) studies have implicated lipid oxidation and Maillard browning as the 2 deleterious reactions responsible for the off flavor development in dry whey products. These reports have identified many common lipid oxidation products including aliphatic aldehydes (C5 to C14), methyl ketones (C4 to C14), and the alcohols 1-pentanol and 1-octen-3-ol, along with furans pyrazines, pyrroles, and pyrans from Maillard reactions.

Free fatty acids, particularly unsaturated fatty acids, are vulnerable to oxidation and are known to be precursors of the aforementioned lipid oxidation products. The presence of FFA constitutes a risk factor for oxidation and the development of off flavor in whey products. Unfortunately, the analysis and quantification of FFA in whey products has been the focus of only limited published research. The methods detailed by Vaghela and Kilara $(1995,1996)$ were not found to be suitable for the rapid analysis of numerous samples that was sought in this study. In response, a solid-phase microextraction technique was used, and the data have been reported elsewhere (Tomaino et al., 2001) and herein. The data reported by Tomaino et al. (2001) and those of Morr and Foegeding (1990) support a possible link between the level of FFA in whey products and poor flavor. Tomaino et al. (2001) reported that a whey protein concentrate (WPC) containing $86.5 \%$ protein contained a 20-fold greater concentration of FFA compared with a whey protein isolate (WPI) containing 92.6\% protein. Morr and Foegeding (1990) reported that solutions of WPI exhibited totally bland or a slightly stale old whey flavor, with intensities lower than 2 on a 5- 
point scale, whereas solutions of WPC received scores greater than 4 for stale old whey flavor. The potential for oxidation that FFA exhibit and the disparity in the concentration within WPC and WPI in conjunction with the sensory data differences support the concept that increased levels of FFA in whey products are a risk factor for subsequent oxidation and off flavor.

The aim of this research was twofold. First, determine if starter cultures influence the oxidative stability and flavor of liquid whey immediately following clarification and pasteurization, and then secondly, determine the impact of storage on both of these attributes. Although the liquid whey that is used in food applications is predominately dried into various products, it is often transported and stored prior to drying. The chemical reactions occurring in liquid whey prior to concentration and drying could be detrimental to the flavor of finished whey ingredients. The proteins in whey are known to avidly bind flavor compounds, including methyl ketones and aldehydes (Mills and Solms, 1984) typically produced during lipid oxidation. Bangs and Reineccius (1981) showed that greater than $50 \%$ of 12 volatile compounds, with a wide range of chemical properties, added to a whey solution containing $7 \%$ protein, were retained during spray drying. If oxidative reactions occur during transportation and storage of liquid whey prior to processing into whey ingredients, then oxidative by-products will have an opportunity to bind to the proteins and be carried through the processing and impact flavor, functionality, and variability. In many cases, the storage and transport of liquid whey is not a factor because it is immediately processed into dry ingredients. Our goal was not to mimic industrial practice, but to use storage conditions similar to pasteurized milk that would ensure limited bacterial growth and exclude drying as a factor in the lipid stability of liquid whey.

\section{MATERIALS AND METHODS}

\section{Starter Culture Preparation}

Frozen stock solutions of Lactococcus lactis spp. lactis (MM380) and Lactococcus lactis spp. cremoris (MM170) were donated by Rhodia (Madison, WI). Stocks were produced by growing each culture in M17 broth (Difco Laboratories, Detroit, MI) supplemented with $10 \%$ lactose at $30^{\circ} \mathrm{C}$. Following growth, glycerol $(10 \% \mathrm{vol} / \mathrm{vol})$ was added to the broth, which was then frozen at $-20^{\circ} \mathrm{C}$. One liter of M17 broth with added lactose was inoculated with each culture and grown overnight every week prior to whey production. Starter cultures that were to be used in combination were grown separately in 500 $\mathrm{mL}$ of broth. The media were centrifuged at $9500 \times \mathrm{g}$ for $20 \mathrm{~min}$. The supernatant was removed and the pellet resuspended in whole milk and frozen by immersion in liquid nitrogen. The frozen cultures were stored at $-80^{\circ} \mathrm{C}$ for no longer than $1 \mathrm{wk}$ prior to whey production. Prior to inoculation into the cheese vat, cultures were allowed to defrost for $30 \mathrm{~min}$ in a room-temperature water bath.

\section{Whey Production}

Twelve 23-L cartons of pasteurized whole milk (3.4\% fat) were obtained from the Dairy and Process Application Laboratory (Department of Food Science at North Carolina University, Raleigh) each week and stored at $4^{\circ} \mathrm{C}$. All of the milk was obtained from the same farm to help reduce variability in the starting material. To a 190-L capacity, steam-jacketed cheese vat (MeyerBlanke, St. Louis, MO), $68 \mathrm{~L}$ of milk was added and slowly heated to $32^{\circ} \mathrm{C}$ while stirring. Starter cultures or $0.05 \%$ (wt/wt) glucono- $\delta$-lactone (GDL; Archer Daniels Midland, Decatur, IL) for the control were stirred into the milk and acid development ( $\mathrm{pH}$ between 6.2 to 6.3) was allowed to occur for $75 \mathrm{~min}$. Then, $0.02 \%$ (vol/vol) CHY-MAX Ultra chymosin (Chr Hansen, Milwaukee, WI) diluted 1:40 with distilled water was stirred in for $5 \mathrm{~min}$. For the control, an additional $0.075 \%$ (wt/wt) glucono- $\delta$-lactone was added along with the coagulant. After $25 \mathrm{~min}$, the curd was cut with 0.64 -cm-wide horizontal and vertical cheese knives and then stirred for $5 \mathrm{~min}$. The curd was then heated to $38^{\circ} \mathrm{C}$ while agitating over a 30-min period, after which time the curd was allowed to settle for $10 \mathrm{~min}$. Whey was then drained to the curd line and disposed. The remaining whey in the vat was drained after $45 \mathrm{~min}$ and initially filtered through cheesecloth, followed by the removal of residual cheese fines with a laboratory clarifier (Westfalia Separator, Oedle, Germany). After the initial separation, the clarifier was disassembled, the fines were removed, and the whey was clarified again. The whey was then pasteurized $\left(77^{\circ} \mathrm{C}, 16 \mathrm{~s}\right)$ with a Cherry Burrell No-Bac Unitherm (model XXI, Cedar Rapids, IA) and directly filled into $125-\mathrm{mL}$ high-density polyethylene bottles (Nalge Co., Rochester, NY). The bottles were immediately frozen at $-20^{\circ} \mathrm{C}\left(\right.$ Fresh) or stored at $4^{\circ} \mathrm{C}$ for 14 days then frozen (Storage). Samples of milk from each day were also taken prior to cheesemaking and stored in a similar fashion. The $\mathrm{pH}$ values were monitored throughout the process to ensure that the starter cultures were growing properly. Four treatments were replicated in 3 different lots of milk over a 3 -wk period and were as follows: MM380, MM170, a combination of MM380 and MM170 (MM380/170), and GDL, the control. 


\section{Dynamic Headspace-Gas Chromatography Analysis}

Samples were defrosted for $1 \mathrm{~h}$ in a water bath $\left(25^{\circ} \mathrm{C}\right)$ and then refrigerated for no longer than $12 \mathrm{~h}$ prior to analysis. Sixteen grams of whey or milk, in duplicate, along with $10 \mu \mathrm{L}$ of an internal standard comprising $0.25 \mathrm{mg}$ of 1-pentanol $/ \mathrm{mL}$ of distilled water and a stir bar were added to a $30-\mathrm{mL}$ headspace vial (Supelco, Bellefonte, PA) and crimp sealed with a teflon/butyl septum (National Scientific, Saudi Arabia). Prior to analysis, all samples were equilibrated to room temperature in a $25^{\circ} \mathrm{C}$ water bath for $30 \mathrm{~min}$. The septum was pierced with a purge and a recovery needle that was attached to a Tekmar (Cincinnati, $\mathrm{OH}$ ) dynamic headspace unit. The samples were purged $(30 \mathrm{~mL} / \mathrm{min})$ onto a Tenax TA trap (Tekmar) with helium for $20 \mathrm{~min}$, followed by a 5 -min desorption at $185^{\circ} \mathrm{C}$ and a 20 -min bake step at $200^{\circ} \mathrm{C}$ before the next analysis. During the purge step, the samples were placed on a stir plate and agitated to aid in volatile release. The desorbed volatile compounds were transferred on to a Hewlett Packard 5890 series II gas chromatograph (Hewlett Packard, Wilmington, DE) equipped with a $30-\mathrm{m}$ DB-1 capillary column (J\&W Scientific, Folsom, CA) with an internal diameter of $0.32 \mathrm{~mm}$ and $3-\mu \mathrm{m}$ film thickness. The temperature was programmed to start at $-20^{\circ} \mathrm{C}$ with a 6min hold, followed by an increase to $60^{\circ} \mathrm{C}$ at a rate of $8^{\circ} \mathrm{C} / \mathrm{min}$, and then an increase to $220^{\circ} \mathrm{C}$ at $6^{\circ} \mathrm{C} / \mathrm{min}$ with a final 5-min hold. The injector and detector were set at $250^{\circ} \mathrm{C}$ and the carrier gas $(\mathrm{He})$ was set at $3.15 \mathrm{~mL} /$ min. A Hewlett Packard MSD 5972 mass spectrometer set at $70-\mathrm{eV}$ ionization potential with a scan range of 35 to 350 atomic mass units was used along with matching of retention times of known compounds to identify volatile compounds. All the compounds were obtained from Sigma-Aldrich (St. Louis, MO). Concentrations were calculated semiquantitatively based on the peak area and known concentration of the internal standard and the peak area of the identified compounds. All the whey samples were analyzed within 1 wk after being frozen.

\section{Free Fatty Acids Analysis}

Whey samples were defrosted in a room-temperature $\left(25^{\circ} \mathrm{C}\right)$ water bath for $1 \mathrm{~h}$. Each sample was adjusted to $\mathrm{pH} 2.0$ with $3.3 \mathrm{M} \mathrm{HCl}$ and then stored at refrigerated temperature until analysis, at which time they were equilibrated to room temperature in water bath $\left(25^{\circ} \mathrm{C}\right)$. Five grams of liquid whey was added to a $10-\mathrm{mL}$ screwcap vial (Supelco) along with $5 \mu \mathrm{L}$ of an internal standard composed of $1 \mathrm{mg}$ of heptadecanoic acid $(\mathrm{C} 17) / \mathrm{mL}$ of methanol ( $1 \mu \mathrm{g} / \mathrm{g}$ internal standards concentration) and a 5/8 $\times 5 / 16$ inch octagonal stirring bar (Fisher Scientific, Pittsburgh, PA). The vial was then sealed with a screw cap fitted with a PTFE/Neoprene septa (Supelco). The septa was punctured with the fiber sheath of a $30-\mu \mathrm{m}$-thick polydimethylsiloxane fiber ( $\mathrm{Su}$ pelco) attached to a fiber holder (Supelco) set to a depth of $1 \mathrm{~cm}$, and then placed into a heating block (Pierce Chemical Co., Rockford, IL) adjusted to $110^{\circ} \mathrm{C}$ with the stirring module set on high. Immediately upon placement in the heating block, the fiber was exposed for 40 min, during which time the block temperature was monitored with a thermocouple. After $40 \mathrm{~min}$, the fiber was retracted and then removed from the vial. Prior to desorption, the fiber holder was adjusted to a depth of $3 \mathrm{~cm}$ and then placed into the injector $\left(250^{\circ} \mathrm{C}\right)$ of a Varian 3700 gas chromatograph (Walnut Creek, CA) equipped with a DB-FFAP column (30 m, $0.25 \mathrm{~mm}$ i.d., $0.25-\mu \mathrm{m}$ film thickness, J\&W Scientific) operating with the split flow off. The temperature program was initially set at $100^{\circ} \mathrm{C}$, held for $2 \mathrm{~min}$, and then increased at a rate of $10^{\circ} \mathrm{C} / \mathrm{min}$ up to $245^{\circ} \mathrm{C}$, and held for $10 \mathrm{~min}$. The fiber remained in the injector for the entire GC run time, at which time the fiber was retracted and removed and the GC was set at $200^{\circ} \mathrm{C}$ for 30 min then returned to $100^{\circ} \mathrm{C}$ for the next run. These steps were added to minimize any possible carryover effects of the fiber or on the column. The fatty acids were detected with a flame-ionized detector set at $250^{\circ} \mathrm{C}$. All samples were analyzed in duplicate. The concentration of FFA for each sample was calculated through the use of response and correction factors as described by Tomaino et al (2001).

\section{Sensory Analysis}

The evaluation of the aroma, flavor, and aftertaste was conducted by a 6 -member, experienced descriptive sensory panel using a 14-point universal intensity scale. Descriptors were developed during 3 initial training sessions and included the aroma notes, cardboardy, milky, sour, diacetyl, and metallic; the flavor notes, sweet, milky, sour, cardboardy, musty, astringency, and tongue and throat burn; and the aftertaste notes, sweet, cardboardy, musty, milky, sour, and astringency. Four room temperature-coded samples were given at random to each panelist in 6-oz glass containers with lids during each session. Reference samples were used at each session to calibrate the panelist and to ensure consistency during the study. Whey samples were all evaluated once within $1 \mathrm{wk}$ after being frozen.

\section{Statistics}

All data were analyzed for statistical differences using SAS statistical software (SAS Inst., Inc., Cary, NC). Analysis of variance and mean separations were per- 
Table 1. Concentration ${ }^{1}$ of volatile compounds in fresh liquid whey and milk.

\begin{tabular}{|c|c|c|c|c|c|}
\hline Volatile $^{2}$ & Milk & GDL & MM170 & MM380/170 & MM380 \\
\hline Acetaldehyde & 23.56 & $17.09^{c}$ & $554.19^{\mathrm{a}}$ & $294.66^{\mathrm{b}}$ & $52.26^{\mathrm{c}}$ \\
\hline Ethanol & 29.81 & $26.69^{\mathrm{c}}$ & $480.93^{\mathrm{a}}$ & $531.10^{\mathrm{a}}$ & $255.54^{\mathrm{b}}$ \\
\hline Acetone & 5000.96 & $2436.22^{\mathrm{a}}$ & $2383.89^{\mathrm{a}}$ & $2372.26^{\mathrm{a}}$ & $2476.10^{\mathrm{a}}$ \\
\hline 2-Propanol & 14.60 & $23.03^{\mathrm{b}}$ & $27.76^{\mathrm{b}}$ & $52.67^{\mathrm{a}}$ & $21.79^{\mathrm{b}}$ \\
\hline Pentane & N/D & N/D & $\mathrm{N} / \mathrm{D}$ & N/D & N/D \\
\hline Dimethyl sulfide & 298.00 & $21.03^{\mathrm{b}}$ & $25.93^{\mathrm{b}}$ & $22.39^{\mathrm{b}}$ & $36.34^{\mathrm{a}}$ \\
\hline 1-Propanol & N/D & $\mathrm{N} / \mathrm{D}$ & $13.37^{\mathrm{a}}$ & $13.93^{\mathrm{a}}$ & $10.72^{\mathrm{b}}$ \\
\hline Diacetyl & 19.10 & $4.85^{\mathrm{d}}$ & $168.08^{\mathrm{a}}$ & $134.49^{b}$ & $82.22^{\mathrm{c}}$ \\
\hline 2-Butanone & 2195.48 & $935.70^{\mathrm{a}}$ & $908.14^{a}$ & $908.29^{a}$ & $938.32^{\mathrm{a}}$ \\
\hline Pentanal & 25.40 & $17.28^{\mathrm{a}}$ & $14.49^{b}$ & $13.93^{\mathrm{b}}$ & $15.08^{\mathrm{b}}$ \\
\hline Hexanal & N/D & $8.10^{\mathrm{b}}$ & $16.01^{\mathrm{a}}$ & $8.55^{\mathrm{b}}$ & $11.56^{\mathrm{ab}}$ \\
\hline 2-Heptanone & 27.60 & $6.53^{\mathrm{a}}$ & $9.43^{\mathrm{a}}$ & $7.93^{\mathrm{a}}$ & $7.52^{\mathrm{a}}$ \\
\hline Phenol & 60.10 & $48.57^{\mathrm{a}}$ & $39.44^{\mathrm{a}}$ & $39.96^{\mathrm{a}}$ & $40.69^{\mathrm{a}}$ \\
\hline Octanal & N/D & $\mathrm{N} / \mathrm{D}$ & $\mathrm{N} / \mathrm{D}$ & $\mathrm{N} / \mathrm{D}$ & N/D \\
\hline 2-Nonanone & $\mathrm{N} / \mathrm{D}$ & $15.12^{\mathrm{a}}$ & $13.38^{\mathrm{a}}$ & $12.42^{\mathrm{a}}$ & $15.09^{\mathrm{a}}$ \\
\hline Nonanal & N/D & $10.53^{\mathrm{a}}$ & $10.67^{\mathrm{a}}$ & $9.36^{\mathrm{a}}$ & $9.81^{\mathrm{a}}$ \\
\hline
\end{tabular}

formed by the PROC ANOVA and DUNCAN procedures, respectively, and correlation values were determined using PROC CORR. All significant differences reported are at least at the $P<0.05$ level unless specified.

\section{RESULTS AND DISCUSSION}

\section{Volatile Analysis and Relation to Sensory Data}

Table 1 contains the volatile compounds identified in milk and fresh liquid whey that were produced in this study. Most of the compounds identified in liquid whey were components partitioned from milk. The data for the 4 treatments suggest that when compared with the control, the starter cultures contributed to production of acetaldehyde, ethanol, diacetyl, 1-propanol, and 2propanol. The MM170 samples contained significantly $(P<0.05)$ greater amounts of acetaldehyde and diacetyl, whereas MM380 contained the least. The MM380/170 combination had intermediate levels of these compounds but contained greater amounts of the 3 alcohols, ethanol, 2-propanol, and 1-propanol, suggesting a synergistic effect of the 2 starter cultures. Many of the volatile compounds present in milk appeared in liquid whey in lower concentrations, presumably due to either dilution or retention within the curd, but some volatile compounds including 1-propanol, hexanal, nonanal, and 2-nonanone were detected in the liquid whey but not in milk (Table 1). These compounds are common volatile lipid oxidation products (VLOP), and it was assumed that their presence indicated that oxidation had been initiated during the cheesemaking and whey pasteurization. The large increase in aldehydes, especially of hexanal, methyl ketones, and pentane in the storage whey, verified the assumption that lipid oxidation had been initiated (Table 2). Hexanal, pentanal, nonanal, heptanone, and pentane all were highest in the MM170 samples, whereas MM380, GDL, and MM380/170 each had progressively lower values. The MM170, which had the highest level of hexanal in the fresh whey (Table 1$)$, had significantly $(P<0.05)$ greater levels of all the VLOP identified compared with the MM380/170 samples. These data strongly suggest that when the 2 starter cultures used in this study were inoculated together, they significantly $(P<0.05)$ reduced the presence of VLOP during $14 \mathrm{~d}$ of refrigerated storage, whereas the MM170 culture alone significantly increased the level of VLOP compared with the control.

Hexanal is an oxidation product originating from linoleic acid (Grosch, 1982) and is often found in whey products. Research by Quach et al. (1999) and Mills (1986) have identified hexanal as the predominant aliphatic aldehyde detected. Lee et al. (1996) reported an increase from $11.3 \mathrm{ng}$ of hexanal/g of whey protein concentrate to $1436.7 \mathrm{ng} / \mathrm{g}$ after $6 \mathrm{~d}$ of accelerated storage. Milk used in the present study and stored along with the whey did not show signs of oxidation, as determined by the level of VLOP. The only changes that occurred were the appearance or increase in 2-propanol, butanol, ethyl acetate, and dimethyl sulfide, whereas acetone and butanone decreased (data not shown). These increases were most likely indicative of psychrotrophic growth. Urbach (1990) inoculated raw milk with psychrotrophic organisms and reported similar results. Sam- 
Table 2. Concentration ${ }^{1}$ of volatile compounds in storage liquid whey.

\begin{tabular}{lcccc}
\hline Volatile $^{2}$ & GDL & MM170 & MM380/170 & MM380 \\
\hline Acetaldehyde & $12.53^{\mathrm{b}}$ & $173.73^{\mathrm{a}}$ & $73.82^{\mathrm{b}}$ & $25.97^{\mathrm{b}}$ \\
Ethanol & $24.60^{\mathrm{c}}$ & $455.21^{\mathrm{a}}$ & $494.92^{\mathrm{a}}$ & $233.54^{\mathrm{b}}$ \\
Acetone & $2296.93^{\mathrm{b}}$ & $2328.16^{\mathrm{ab}}$ & $2301.21^{\mathrm{ab}}$ & $2383.78^{\mathrm{a}}$ \\
2-Propanol & $22.43^{\mathrm{b}}$ & $28.96^{\mathrm{b}}$ & $53.21^{\mathrm{a}}$ & $21.99^{\mathrm{b}}$ \\
Pentane & $24.01^{\mathrm{bc}}$ & $41.60^{\mathrm{a}}$ & $17.44^{\mathrm{c}}$ & $31.69^{\mathrm{ab}}$ \\
Dimethyl sulfide & $17.74^{\mathrm{a}}$ & $18.47^{\mathrm{a}}$ & $18.26^{\mathrm{a}}$ & $27.03^{\mathrm{a}}$ \\
1-Propanol & N/D & $13.96^{\mathrm{a}}$ & $13.51^{\mathrm{a}}$ & $11.55^{\mathrm{b}}$ \\
Diacetyl & $5.55^{\mathrm{c}}$ & $167.21^{\mathrm{a}}$ & $135.49^{\mathrm{a}}$ & $95.31^{\mathrm{b}}$ \\
2-Butanone & $874.88^{\mathrm{ab}}$ & $868.89^{\mathrm{ab}}$ & $862.91^{\mathrm{b}}$ & $896.17^{\mathrm{a}}$ \\
Pentanal & $70.24^{\mathrm{a}}$ & $84.08^{\mathrm{a}}$ & $43.97^{\mathrm{b}}$ & $74.84^{\mathrm{a}}$ \\
Hexanal & $597.00^{\mathrm{bc}}$ & $907.60^{\mathrm{a}}$ & $395.70^{\mathrm{c}}$ & $674.20^{\mathrm{ab}}$ \\
2-Heptanone & $37.65^{\mathrm{ab}}$ & $59.32^{\mathrm{a}}$ & $24.01^{\mathrm{b}}$ & $49.60^{\mathrm{a}}$ \\
Phenol & $35.76^{\mathrm{a}}$ & $32.70^{\mathrm{a}}$ & $32.58^{\mathrm{a}}$ & $31.78^{\mathrm{a}}$ \\
Octanal & $36.00^{\mathrm{ab}}$ & $56.60^{\mathrm{a}}$ & $20.71^{\mathrm{b}}$ & $47.92^{\mathrm{a}}$ \\
2-Nonanone & $47.88^{\mathrm{a}}$ & $35.47^{\mathrm{b}}$ & $42.66^{\mathrm{ab}}$ & $41.93^{\mathrm{ab}}$ \\
Nonanal & $28.98^{\mathrm{b}}$ & $44.45^{\mathrm{a}}$ & $21.39^{\mathrm{b}}$ & $32.06^{\mathrm{ab}}$ \\
\hline
\end{tabular}

a,b,c Means within rows with different letters are statistically different $(P<0.05)$.

${ }^{1}$ Concentration $=$ ng of volatile/g of liquid whey or milk.

${ }^{2}$ Volatiles identified by mass spectrometry and retention times. GDL = glucono- $\delta$-lactone (control), MM170 = Lactococcus lactis spp. cremoris, MM380 = Lactococcus lactis spp. lactis, MM380/170 = a combination of MM170 and MM380 ( $=6)$.

ples of milk were taken after the milk was poured into the cheese vat, and presumably the undesired contamination occurred at this point. The whey samples were directly filled from the pasteurizer and no evidence $(\mathrm{pH}$ decline or volatile compounds) of psychrotrophic or further starter culture growth was detected. The $\mathrm{pH}$ values averaged 6.22 with a range between 6.14 and 6.33 in all the pasteurized whey samples and no significant differences between treatments or during storage were detected. The slight decrease in many of the volatile compounds, such as acetone and butanone, in the stored whey (Table 3) was likely the result of the matrix

Table 3. The effect of time on the concentration ${ }^{1}$ of volatile compounds in liquid whey.

\begin{tabular}{lcc}
\hline Volatile $^{2}$ & Fresh & Storage \\
\hline Acetaldehyde & $229.55^{\mathrm{b}}$ & $71.51^{\mathrm{a}}$ \\
Ethanol & $323.57^{\mathrm{a}}$ & $302.07^{\mathrm{a}}$ \\
Acetone & $2417.12^{\mathrm{a}}$ & $2327.52^{\mathrm{b}}$ \\
2-Propanol & $31.31^{\mathrm{a}}$ & $31.65^{\mathrm{a}}$ \\
Pentane & $\mathrm{N} / \mathrm{D}$ & 28.69 \\
Dimethyl Sulfide & $26.42^{\mathrm{a}}$ & $20.38^{\mathrm{b}}$ \\
1-Propanol & $9.51^{\mathrm{a}}$ & $9.75^{\mathrm{a}}$ \\
Diacetyl & $97.41^{\mathrm{a}}$ & $100.89^{\mathrm{a}}$ \\
2-Butanone & $922.61^{\mathrm{a}}$ & $875.71^{\mathrm{b}}$ \\
Pentanal & $15.19^{\mathrm{b}}$ & $68.28^{\mathrm{a}}$ \\
Hexanal & $11.06^{\mathrm{b}}$ & $643.63^{\mathrm{a}}$ \\
2-Heptanone & $7.85^{\mathrm{b}}$ & $42.65^{\mathrm{a}}$ \\
Phenol & $42.16^{\mathrm{a}}$ & $33.20^{\mathrm{b}}$ \\
Octanal & $\mathrm{N} / \mathrm{D}$ & 40.31 \\
2-Nonanone & $14.00^{\mathrm{b}}$ & $41.99^{\mathrm{a}}$ \\
Nonanal & $10.09^{\mathrm{b}}$ & $31.72^{\mathrm{a}}$ \\
\hline
\end{tabular}

${ }^{\mathrm{a}, \mathrm{b}}$ Means within rows with different letters are statistically different $(P<0.05)$.

${ }^{1}$ Concentration $=$ ng of volatile/g of liquid whey or milk.

${ }^{2}$ Volatiles identified by mass spectrometry and retention time $(\mathrm{n}=$ 24). change induced by the increase in VLOP or associations with proteins that decreased their headspace values. The greater than threefold decrease in acetaldehyde may relate to this compound's ability, as with other aliphatic aldehydes, to bind to or associate with proteins (Gardner, 1979).

The importance of the fermentation compounds produced by the starter culture and some of the more volatile compounds derived from milk, such as acetone, on whey ingredients is probably limited because they have not been typically identified in the whey volatile profiles; presumably, they are removed during processing. In contrast, the VLOP and hydroperoxides produced during lipid oxidation are known to associate with the whey protein ingredients either through entrapment within the matrix (Kinsella, 1989) or through hydrophobic interactions (Mills and Solms, 1984) and possibly covalent linkages with $\varepsilon$ - and $\alpha$-amino groups of protein (Hidalgo and Kinsella, 1989). These interactions would allow for the carryover of these compounds into whey products. Furthermore, the data in this study suggest that the induction of lipid oxidation occurred during the cheesemaking and whey processing, and that it escalated during storage. If this holds true for all whey (i.e., the induction of lipid oxidation prior to further processing), then dry whey ingredients would be susceptible to oxidation during storage. This may explain the large increase in hexanal reported by Lee et al. (1996) during accelerated storage of whey protein concentrate.

An array of descriptors was evaluated in fresh and stored liquid whey. Table 4 lists the terms that were found to statistically vary between treatments in the 
Table 4. Sensory scores $^{1}$ of fresh liquid whey.

\begin{tabular}{lllll}
\hline Item & GDL & MM170 & MM380/170 & MM380 \\
\hline Aroma & & & & \\
Milky & $1.95^{\mathrm{b}}$ & $2.50^{\mathrm{a}}$ & $2.35^{\mathrm{a}}$ & $2.20^{\mathrm{a}}$ \\
Sour & $1.15^{\mathrm{c}}$ & $2.35^{\mathrm{a}}$ & $2.15^{\mathrm{a}}$ & $1.65^{\mathrm{b}}$ \\
Flavor & & & & \\
Sweet & $2.59^{\mathrm{a}}$ & $2.04^{\mathrm{b}}$ & $2.39^{\mathrm{ab}}$ & $2.69^{\mathrm{a}}$ \\
Milky & $2.40^{\mathrm{b}}$ & $2.84^{\mathrm{a}}$ & $2.75^{\mathrm{ab}}$ & $2.90^{\mathrm{a}}$ \\
Sour & $1.50^{\mathrm{b}}$ & $2.50^{\mathrm{a}}$ & $2.30^{\mathrm{a}}$ & $2.15^{\mathrm{a}}$ \\
Cardboardy & $1.21^{\mathrm{b}}$ & $1.91^{\mathrm{a}}$ & $1.51^{\mathrm{ab}}$ & $1.61^{\mathrm{a}}$ \\
Astringency & $1.70^{\mathrm{b}}$ & $2.00^{\mathrm{ab}}$ & $2.25^{\mathrm{a}}$ & $2.30^{\mathrm{a}}$ \\
Aftertaste & & & & \\
Sweet & $2.59^{\mathrm{a}}$ & $2.14^{\mathrm{b}}$ & $2.44^{\mathrm{ab}}$ & $2.99^{\mathrm{a}}$ \\
Cardboardy & $1.35^{\mathrm{b}}$ & $1.80^{\mathrm{a}}$ & $1.55^{\mathrm{ab}}$ & $1.50^{\mathrm{ab}}$ \\
Sour & $1.55^{\mathrm{b}}$ & $2.25^{\mathrm{a}}$ & $2.30^{\mathrm{a}}$ & $2.10^{\mathrm{a}}$ \\
Astringency & $2.30^{\mathrm{b}}$ & $2.30^{\mathrm{b}}$ & $2.80^{\mathrm{a}}$ & $2.60^{\mathrm{ab}}$ \\
\hline
\end{tabular}

a,b,c Means within rows with different letters are statistically different $(P<0.05)$.

${ }^{1}$ Attributes were evaluated using a 14-point universal intensity scale $(1=$ lowest intensity, $14=$ highest intensity). GDL $=$ glucono$\delta$-lactone (control), MM170 = Lactococcus lactis subsp. cremoris, MM380 = Lactococcus lactis subsp. lactis, MM380/170 = a combination of MM170 and MM380 (n = 3).

fresh whey. The milky and sour notes were lowest in the control whey (GDL). This may be attributed to the production of fermentation products, such as acetaldehyde, ethanol, and diacetyl in the whey produced with starter culture. The cardboardy flavor and aftertaste of the fresh control (GDL) were significantly $(P<0.05)$ lower than that of the MM170 sample, indicating oxidation was already initiated in the fresh liquid whey. A significant correlation between acetaldehyde, ethanol, and diacetyl and sour aroma was found (Table 5). Acetaldehyde was likely responsible for the sour note, as it is known to impart sour attributes in food. Ahmed et al. (1978) reported the threshold value of acetaldehyde to be $17 \mathrm{ppb}$ in water, which is close to the reported value for the GDL samples and much lower than for the other whey treatments (Table 1). The astringency in all the whey samples was problematic for many of
Table 6. The effect of time on the sensory ${ }^{1}$ attributes of fresh and storage liquid whey.

\begin{tabular}{lll}
\hline Item & Fresh & Storage \\
\hline Aroma & & \\
Cardboardy & $1.50^{\mathrm{b}}$ & $1.86^{\mathrm{a}}$ \\
$\quad$ Sour & $1.83^{\mathrm{a}}$ & $1.51^{\mathrm{b}}$ \\
Flavor & $1.56^{\mathrm{b}}$ & $1.95^{\mathrm{a}}$ \\
$\quad$ Cardboardy & $1.55^{\mathrm{b}}$ & $1.92^{\mathrm{a}}$ \\
Aftertaste & $2.50^{\mathrm{b}}$ & $2.76^{\mathrm{a}}$ \\
$\quad$ Cardboardy & Astringency & \\
\hline
\end{tabular}

${ }^{a, b}$ Means within rows of each treatment with different letters are statistically different $(P<0.05)$.

${ }^{1}$ Attributes were evaluated using a 14-point universal intensity scale $(1=$ lowest intensity, $14=$ highest intensity $)(n=12)$.

the panelists. Although scored at low intensity, it had a propensity to persist in the palate well after expectoration of the samples. Astringency in milk has been attributed to both proteolytic products of casein produced by plasmin and psychrotrophic proteases (Harwalkar et al., 1993) and protein-salt complexes formed during heating (Josephson et al., 1967).

Cardboardy flavors in dairy products are associated with lipid oxidation products (Hammond, 1989). Research by Hall and Andersson (1985) reported a strong relationship between cardboard-like flavor and the increasing level of straight-chain aldehydes during storage of whole milk powder. In this study, the cardboardy aroma, flavor, and aftertaste all significantly $(P<0.05)$ increased during storage (Table 6) and significant correlations were found between cardboardy flavor and aftertaste with hexanal concentration, along with many other VLOP (Table 5). Dynamic headspace analysis of cardboard soaked in warm water showed that nonanal was the predominant volatile followed by hexanal, octanal, and heptanal (data not shown), which supports their possible contribution to cardboardy flavor. Widder and Grosch (1997) found that the alkenal, 2-nonenal,

Table 5. Correlations ${ }^{1}$ between flavor attributes and the concentration of constituents in fresh and stored liquid whey.

\begin{tabular}{|c|c|c|c|c|c|c|}
\hline \multirow[b]{2}{*}{ Compound } & \multicolumn{2}{|c|}{ Sour aroma } & \multicolumn{2}{|c|}{ Cardboardy flavor } & \multicolumn{2}{|c|}{ Cardboardy aftertaste } \\
\hline & $\mathrm{r}$ & $P$-value & $\mathrm{r}$ & $P$-value & $\mathrm{r}$ & $P$-value \\
\hline Acetaldehyde & 0.868 & 0.005 & - & - & - & - \\
\hline Ethanol & 0.839 & 0.009 & - & - & - & - \\
\hline Diacetyl & 0.813 & 0.014 & - & - & - & - \\
\hline Pentanal & - & - & 0.693 & 0.057 & 0.693 & 0.057 \\
\hline Hexanal & - & - & 0.708 & 0.049 & 0.748 & 0.033 \\
\hline Nonanal & - & - & 0.688 & 0.059 & 0.758 & 0.029 \\
\hline 2-heptanone & - & - & 0.683 & 0.062 & 0.702 & 0.052 \\
\hline 2-nonanone & - & - & 0.702 & 0.052 & 0.647 & 0.083 \\
\hline 1-dodecene & - & - & 0.728 & 0.041 & 0.757 & 0.030 \\
\hline Linoleic acid & - & - & -0.770 & 0.026 & -0.816 & 0.014 \\
\hline
\end{tabular}

${ }^{1}$ Correlations were made between fresh $(n=4)$ and storage $(n=4)$ analytical and sensory data. 
Table 7. The effect of treatment on the free fatty acid concentration ${ }^{1}$ of liquid whey.

\begin{tabular}{lcccc}
\hline Fatty acid & MM380/170 & GDL & MM380 & MM170 \\
\hline C6 & $1.08^{\mathrm{a}}$ & $0.99^{\mathrm{a}}$ & $1.06^{\mathrm{a}}$ & $1.14^{\mathrm{a}}$ \\
C8 & $0.83^{\mathrm{a}}$ & $0.83^{\mathrm{a}}$ & $0.86^{\mathrm{a}}$ & $0.86^{\mathrm{a}}$ \\
C10 & $0.65^{\mathrm{a}}$ & $0.67^{\mathrm{a}}$ & $0.70^{\mathrm{a}}$ & $0.64^{\mathrm{a}}$ \\
C12 & $0.44^{\mathrm{b}}$ & $0.43^{\mathrm{b}}$ & $0.48^{\mathrm{a}}$ & $0.44^{\mathrm{b}}$ \\
C14 & $1.19^{\mathrm{b}}$ & $1.15^{\mathrm{b}}$ & $1.29^{\mathrm{a}}$ & $1.19^{\mathrm{b}}$ \\
C16 & $3.91^{\mathrm{bc}}$ & $3.83^{\mathrm{c}}$ & $4.09^{\mathrm{a}}$ & $4.00^{\mathrm{ab}}$ \\
C16:1 & $0.23^{\mathrm{a}}$ & $0.21^{\mathrm{a}}$ & $0.22^{\mathrm{a}}$ & $0.23^{\mathrm{a}}$ \\
C18 & $2.27^{\mathrm{a}}$ & $2.39^{\mathrm{a}}$ & $2.31^{\mathrm{a}}$ & $2.28^{\mathrm{a}}$ \\
C18:1 & $3.15^{\mathrm{a}}$ & $3.06^{\mathrm{a}}$ & $3.35^{\mathrm{a}}$ & $3.11^{\mathrm{a}}$ \\
C18:2 & $0.85^{\mathrm{a}}$ & $0.81^{\mathrm{ab}}$ & $0.86^{\mathrm{a}}$ & $0.71^{\mathrm{b}}$ \\
Total & 14.61 & 14.37 & 15.23 & 14.60 \\
\hline
\end{tabular}

a,b,c Means within rows with different letters are statistically different $(P<0.05)$

${ }^{1}$ Concentration $=\mu \mathrm{g}$ of $\mathrm{FFA} / \mathrm{g}$ of liquid whey. GDL $=$ Glucono- $\delta$ lactone (control), MM170 = Lactococcus lactis subsp. cremoris, MM380 = Lactococcus lactis subsp. lactis, MM380/170 = a combination of MM170 and MM380 ( $=12)$.

was responsible for the cardboardy off flavor of butter oil. They concluded that the autooxidation of palmitoleic acid (16:1) was responsible for the formation of 2-nonenal, and it resulted in a cardboard off flavor. Palmitoleic acid was identified in liquid whey in this study (Table 7), but no significant change occurred during storage and no alkenals were identified in liquid whey, and only 2-octenal was found in the cardboard water. Research by Hammond and Seals (1972) demonstrated that the addition of oct-1-en-3-one and octanal together to milk produced an oxidized flavor in milk that was mostly described as a cardboard flavor. These examples clearly demonstrate that it is possible that many different compounds or combinations of VLOP can induce cardboard flavors. Future research should focus on the ability of particular compounds to predict cardboard or oxidized flavors in whey products.

The absence of the fermentation flavor compounds reported herein in volatile analyses of whey protein concentrate by other researchers, presumably negates their importance, but the removal of the low-molecularweight volatile compounds is likely to impact the sensory properties of the resultant whey products. Given the propensity of whey proteins to bind higher-molecular-weight VLOP, the removal of the more abundant volatile compounds might influence the resultant sensory properties by lowering favorable attributes, such as milkiness, while increasing the detection of oxidative notes.

\section{Free Fatty Acids and Relation to Sensory Data}

The concentration of FFA in each whey treatment is shown in Table 7. The data shows that the MM380 whey contained significantly $(P<0.05)$ greater levels
Table 8. The effect of time on the concentration ${ }^{1}$ of free fatty acids in liquid whey.

\begin{tabular}{lcc}
\hline Fatty acid & Fresh & Storage \\
\hline C6 & $1.12^{\mathrm{a}}$ & $1.01^{\mathrm{a}}$ \\
C8 & $0.87^{\mathrm{a}}$ & $0.83^{\mathrm{a}}$ \\
C10 & $0.67^{\mathrm{a}}$ & $0.66^{\mathrm{a}}$ \\
C12 & $0.45^{\mathrm{a}}$ & $0.45^{\mathrm{a}}$ \\
C14 & $1.22^{\mathrm{a}}$ & $1.20^{\mathrm{a}}$ \\
C16 & $4.01^{\mathrm{a}}$ & $3.90^{\mathrm{b}}$ \\
C16:1 & $0.23^{\mathrm{a}}$ & $0.21^{\mathrm{a}}$ \\
C18 & $2.38^{\mathrm{a}}$ & $2.25^{\mathrm{a}}$ \\
C18:1 & $3.33^{\mathrm{a}}$ & $3.00^{\mathrm{b}}$ \\
C18:2 & $0.86^{\mathrm{a}}$ & $0.75^{\mathrm{b}}$ \\
Total & 15.13 & 14.28 \\
\hline
\end{tabular}

${ }^{\mathrm{a}, \mathrm{b}}$ Means within rows with different letters are statistically different $(P<0.05)$.

${ }^{1}$ Concentration $=\mu \mathrm{g}$ of FFA/g of liquid whey $(\mathrm{n}=24)$.

of lauric (C12) and myristic acid (C14) than the other treatments and significantly $(P<0.05)$ greater palmitic acid (C16) levels than the MM380/170 and control whey. These data suggest that the MM380 starter culture contributed to greater levels of FFA in the liquid whey, presumably through greater lipolysis. Because the aim of this research was to study the oxidative stability of liquid whey the FFA were analyzed in the storage samples and the effects of time were statistically analyzed (Table 8). Significant declines in oleic (C18:1), linoleic (C18:2), and palmitic acid occurred during storage. When the sensory and FFA were compared, significant correlations between the decrease in linoleic acid (C18:2) and the increase in cardboardy flavor and aftertaste were found (Table 5). Neither palmitic nor oleic acid were found to significantly $(P<0.05)$ correlate with any of the cardboard attributes studied (data not shown). These data implicates the presence of linoleic acid in whey as a potential risk factor for oxidation and off flavor development.

\section{CONCLUSIONS}

This research clearly demonstrated that Lactococcus lactis starter cultures, commonly used to produce Cheddar cheese, are able to influence the flavor and oxidative stability of liquid whey. Important correlations between the decrease in FFA and increase in hexanal and cardboard sensory attributes were demonstrated in liquid whey. These characteristics have been commonly attributed to side effects from the processing of liquid whey into dry ingredients and its subsequent storage, but this research suggests that lipid oxidation was initiated in the production of the liquid whey and accelerated during $14 \mathrm{~d}$ of refrigerated storage. More research focused on understanding the poor stability of liquid whey is necessary so that measures can be taken to 
prevent oxidative deterioration. The improved understanding of these parameters could allow for the manufacture of higher-quality, more consistent whey products with greater application in the food industry. Oxidation cannot only affect flavor deterioration but it can have adverse effects on the functional properties of whey by altering the physiochemical properties of the whey proteins (Stapelfeldt and Skibsted, 1994) and possibly causing problems with consistency. The evaluation of a wider range of starter cultures on the oxidative stability of liquid is also necessary. The production of whey from Cheddar cheese on a pilot-plant scale limited our ability to evaluate a greater range of starter cultures, but the significant differences in the levels of volatile compounds, FFA, and sensory scores in closely related starter cultures justifies future research focused on a wider range of starter cultures from a variety of cheeses.

\section{REFERENCES}

Ahmed, E. M., R. A. Dennison, and R. A. Shaw. 1978. Effect of selected oil and essence volatile compounds on flavor quality of pumpout orange juice. J. Agric. Food Chem. 26:368-372.

American Dairy Products Institute. 2002. Whey Products: 2001 Utilization and Production Trends. Am. Dairy Prod., Chicago, IL.

Bangs, W. E., and G. A. Reineccius. 1981. Influence of dryer infeed matrices on the retention of volatile flavor compounds during spray drying. J. Food Sci. 47:254-259.

Ferretti, A., and V. P. Flanagan. 1971a. Nonenzymatic browning in edible spray-dried whey. Identification of some volatile components. J. Dairy Sci. 54:1769-1771.

Ferretti, A., and V. P. Flanagan. 1971b. Volatile constituents of whey powder subjected to accelerated browning. J. Dairy Sci. 54:1764-1768.

Gardner, H. W. 1979. Lipid hydroperoxide reactivity with proteins and amino acids: A review. J. Agric. Food Chem. 27:220-229.

Grosch, W. 1982. Lipid degradation products and flavour. Pages 325398 in Food Flavours Part A: Introduction. I. D. Morton and A. J. Macleod, ed. Elsevier, Amsterdam, The Netherlands.

Hall, G., and J. Andersson. 1985. Flavor changes in whole milk powder during storage. III. Relationships between flavor properties and volatile compounds. J. Food Qual. 7:237-253.

Hammond, E. G. 1989. The flavor of dairy products. Pages 222-236 in Flavor Chemistry of Lipid Foods. D. B. Min and T. H. Smouse, ed. Am. Oil Chem. Soc., Champaign, IL.

Hammond, E. G., and R. G. Seals. 1972. Oxidized flavor in milk and its simulation. J. Dairy Sci. 55:1567-1569.

Harwalkar, V. R., H. Cholette, R. C. McKellar, and D. B. Emmons. 1993. Relation between proteolysis and astringent off-flavor in milk. J. Dairy Sci. 76:2521-2527.

Hidalgo, F. J., and J. E. Kinsella. 1989. Changes induced in $\beta$-lactoglobulin B following interactions with linoleic acid 13-hydroperoxide. J. Agric. Food Chem. 37:860-866.

Jayaprakasha, H. M., and H. Brueckner. 1999. Whey protein concentrate: A potential functional ingredient for the food industry. J. Food Sci. Tech. 36:189-204.
Josephson, R. V., E. L. Thomas, C. V. Morr, and S. T. Coulter. 1967. Relation of heat-induced changes in protein-salt constituents of astringency in milk systems. J. Dairy Sci. 50:1376-1383.

Kinsella, J. E. 1989. Flavor perception and binding to food components. Pages 376-403 in Flavor Chemistry of Lipid Foods. D. B. Min and T. H. Smouse, ed. Am. Oil Chem. Soc., Champaign, IL.

Laye, I., D. Karleskind, and C. V. Morr. 1995. Chemical and volatile organic compounds composition of whey protein concentrate. Pages 769-784 in Food Flavors: Generation, Analysis and Process Influence. G. Charalambous, ed. Elsevier, New York, NY.

Lee, Y. B., I. Laye, Y. D. Kim, and C. V. Morr. 1996. Formation of volatile compounds in whey protein concentrate during elevated temperature storage as a function of water activity. Int Dairy J. $6: 485-496$

Lee, Y. B., and C. V. Morr. 1994. Changes of headspace volatile compounds due to oxidation of milk fat during storage of dried dairy products. Pages $98-107$ in Lipids in Food Flavors. C. T. Ho and T. G. Hartman, ed. Am. Chem. Soc., Washington, DC.

Mills, O. E. 1986. A headspace sampling method for monitoring flavour volatiles of protein products. N. Z. J. Dairy Sci. 21:49-56.

Mills, O. E., and A. J. Broome. 1998. Isolation of flavor compounds from protein material. Pages 85-91 in Flavor Analysis: Development in Isolation and Characterization. C. J. Mussinan and M. J. Morello, ed. Am. Chem. Soc., Washington, DC.

Mills, O. E., and J. Solms. 1984. Interaction of selected flavour compounds with whey proteins. Lebensm-Wiss. Technol. 17:331-335.

Morr, C. V., and E. A. Foegeding. 1990. Composition and functionality of commercial whey and milk protein concentrates and isolates: A status report. Food Technol. 44:100-111.

Morr, C. V., and E. Y. W. Ha. 1991. Off-flavors of whey protein concentrates: A literature review. Int. Dairy J. 1:1-11.

Morr, C. V., and E. Y. W. Ha. 1993. Whey protein concentrates and isolates: Processing and functional properties. Crit Rev. Food Sci. Nutr. 33:431-476.

Quach, M. L., X. D. Chen, and R. J. Stevenson. 1999. Headspace sampling of whey protein concentrate solutions using solid-phase microextraction. Food Res. Int. 31:371-379.

Regester, G. O., G. H. McIntosh, V. W. K. Lee, and G. W. Smithers. 1996. Whey proteins as nutritional and functional food ingredients. Food Aust. 48:123-127.

Stapelfeldt, H., and L. H. Skibsted. 1994. Modification of $\beta$-lactoglobulin by aliphatic aldehydes in aqueous solution. J. Dairy Res. 61:209-219.

Stevenson, R. J., and X. D. Chen. 1996. A study of volatile "trapping" in spray dried whey protein concentrate by "crushing" and/or vacumming, and detection by solid-phase microextraction/gas chromatography/mass spectrometry. Food Res. Int. 29:495-504.

Tomaino, R. M., J. D. Parker, and D. K. Larick. 2001. Analysis of free fatty acids in whey products by solid-phase microextraction. J. Agric. Food Chem. 49:3993-3998.

Urbach, G. 1990. Headspace volatiles from cold-storage raw milk. Aust J. Dairy Tech. 45:80-85.

Vaghela, M. N., and A. Kilara. 1995. A rapid method for extraction of total lipids from whey protein concentrates and separation of lipid classes with solid-phase extraction. J. Am. Oil Chem. Soc. 72:1117-1121.

Vaghela, M., and A. Kilara. 1996. Lipid composition of whey protein concentrates manufactured commercially and in the laboratory. J. Dairy Sci. 79:1172-1183.

Widder, S., and W. Grosch. 1997. Precursors of 2-nonenals causing the cardboard off-flavour in butter oil. Nahrung 41:42-45.

Yang, J., W. L. Li, and W. J. Harper. 1998. Use of solid phase microextraction of volatile compounds in whey protein concentrate. Milchwissenschaft 53:209-212. 